OPEN ACCESS

Edited by:

Amy Rasley,

Lawrence Livermore National Laboratory, USA

Reviewed by:

Adam Cunningham

University of Birmingham, UK Julio Aliberti,

Cincinnati Children's Hospital Medical

Center, USA

${ }^{*}$ Correspondence: Diana Bahia

dianabahia@hotmail.com

Specialty section:

This article was submitted to

Microbial Immunology,

a section of the journal

Frontiers in Microbiology

Received: 11 January 2016 Accepted: 11 March 2016 Published: 31 March 2016

Citation:

Watanabe Costa R, da Silveira JF and Bahia D (2016) Interactions between Trypanosoma cruzi Secreted Proteins and Host Cell Signaling

Pathways. Front. Microbiol. 7:388. doi: 10.3389/fmicb.2016.00388

\section{Interactions between Trypanosoma cruzi Secreted Proteins and Host Cell Signaling Pathways}

\author{
Renata Watanabe Costa ${ }^{1}$, Jose F. da Silveira ${ }^{1}$ and Diana Bahia ${ }^{1,2 *}$ \\ ${ }^{1}$ Departamento de Microbiologia, Imunologia e Parasitologia, Escola Paulista de Medicina, Universidade Federal de São \\ Paulo, São Paulo, Brazil, ² Departamento de Biologia Geral, Instituto de Ciências Biológicas, Universidade Federal de Minas \\ Gerais, Minas Gerais, Brazil
}

Chagas disease is one of the prevalent neglected tropical diseases, affecting at least 6-7 million individuals in Latin America. It is caused by the protozoan parasite Trypanosoma cruzi, which is transmitted to vertebrate hosts by blood-sucking insects. After infection, the parasite invades and multiplies in the myocardium, leading to acute myocarditis that kills around $5 \%$ of untreated individuals. T. cruzi secretes proteins that manipulate multiple host cell signaling pathways to promote host cell invasion. The primary secreted lysosomal peptidase in T. cruzi is cruzipain, which has been shown to modulate the host immune response. Cruzipain hinders macrophage activation during the early stages of infection by interrupting the NF-kB P65 mediated signaling pathway. This allows the parasite to survive and replicate, and may contribute to the spread of infection in acute Chagas disease. Another secreted protein P21, which is expressed in all of the developmental stages of T. cruzi, has been shown to modulate host phagocytosis signaling pathways. The parasite also secretes soluble factors that exert effects on host extracellular matrix, such as proteolytic degradation of collagens. Finally, secreted phospholipase A from T. cruzi contributes to lipid modifications on host cells and concomitantly activates the PKC signaling pathway. Here, we present a brief review of the interaction between secreted proteins from T. cruzi and the host cells, emphasizing the manipulation of host signaling pathways during invasion.

Keywords: $T$. cruzi, secretome, secreted proteins, virulence factor, host parasite interaction, host cell signaling, host cell invasion, Chagas disease

\section{INTRODUCTION}

\section{Trypanosoma cruzi: Life Cycle and Chagas Disease}

Chagas disease is caused by the protozoan parasite Trypanosoma cruzi, affects 6-7 million individuals, primarily in Latin America, and is associated with negative economic impacts in developing countries (http://www.who.int/mediacentre/factsheets/fs340/en/). T. cruzi is transmitted to vertebrate hosts by the triatomine vector Triatoma infestans. Despite its high incidence and economic costs, Chagas disease remains a neglected tropical disease; it does not have an effective pharmacological treatment and there are minimal investments in finding a cure for Chagas disease (Clayton, 2010; Souza et al., 2010). The life cycle of T. cruzi has four developmental phases that occur in the hematophagous insect vector and bloodstream and tissues 
of mammalian hosts (Souza et al., 2010). The epimastigote (EPI) is a non-infectious replicative form found in the vector's digestive tract. The EPI differentiates into the metacyclic trypomastigote (MT), which is transmitted to mammals through the insect's feces during a blood meal or by the oral route. The MT invade mammalian host cells where they transform into an amastigote (AMA) that replicates intracellularly. After a multiple rounds of replication, the AMAs differentiate back into trypomastigotes (TCTs), which are released into the extracellular milieu when the host cell is disrupted. TCTs can invade neighboring host cells or be released into the blood stream where they can infect other tissues or be ingested by a feeding insect. Once the host has been infected, the parasite can invade and multiply in the myocardium, leading to acute myocarditis, which kills around $5 \%$ of untreated individuals (Ponce et al., 2013).

Similar to other intracellular protozoa, $T$. cruzi is an intracellular parasite that invades different types of cells to evade the host immune system (Guiñazú et al., 2007). Intracellular parasites have complex lifecycles that involve several developmental stages, and usually contain multiple secreted proteins that can manipulate host cell signaling pathways to promote parasite adhesion, recognition, and invasion (Burleigh and Woolsey, 2002). The complex interplay between proteins secreted by $T$. cruzi that affect the host cell environment or contribute to immune evasion likely influences the outcome of infection. Understanding the role of secreted proteins during T. cruzi infection is critical to deepen the knowledge of the pathogenesis of Chagas disease (McConville et al., 2002).

\section{T. cruzi Secretome}

In eukaryotes, secreted proteins typically contain an $\mathrm{N}$-terminal signal peptide that directs them to the classical endoplasmic reticulum (ER)/Golgi-dependent secretion pathway. Secretory proteins that do not contain the signal peptide are secreted outside the plasma membrane using non-classical secretory pathways including, membrane-bound extracellular vesicles (EVs), such as exosomes and ectosomes (Nickel and Seedorf, 2008; Simpson and Mathivanan, 2012). Only a small fraction $(\sim 9 \%)$ of the proteins in the T. cruzi secretome contain an N-terminal signal peptide suggesting that they are secreted by classical pathways (Bayer-Santos et al., 2013), the remaining proteins are likely secreted by non-classical pathways (Torrecilhas et al., 2009, 2012; Bayer-Santos et al., 2013; Marcilla et al., 2014).

Secretion or shedding of EVs by $T$. cruzi can occur spontaneously or be induced by nutritional or chemical stress (da Silveira et al., 1979; Torrecilhas et al., 2009, 2012; BayerSantos et al., 2013; Marcilla et al., 2014). A considerable number of the T. cruzi secreted/excreted proteins have been characterized at the structural and functional levels. Some of the secreted T. cruzi proteins, such as the trans-sialidase (TS) glycoproteins (TS/SAPA, Tc85, gp82, gp90, CRP, TESA), mucin-associated surface proteins (MASP), cruzipain, gp63, mucins, and serine, alanine-, and proline-rich proteins (SAP), are associated with the plasma membrane via a glycosylphosphatidylinositol (GPI) anchor (Torrecilhas et al., 2009, 2012; Bayer-Santos et al., 2013; Marcilla et al., 2014). Several of these proteins (e.g.,
TS/SAPA, CRP, mucins) are also spontaneously shed from the parasite surface in a soluble form that lacks the GPI anchor, possibly due to cleavage by an endogenous phospholipase C (Affranchino et al., 1989; de Almeida and Heise, 1993; Bartholomeu et al., 2009; de Pablos et al., 2011; Cánepa et al., 2012a). Others (e.g., Tc85) are shed with the GPI anchor linked to membrane vesicles (Zingales et al., 1985; Abuin et al., 1996a).

Trypomastigotes and AMAs release EVs containing virulence factors involved in: (i) host cell invasion and intracellular parasite development, such as the TS and TS-like proteins (Zingales et al., 1985; Gonçalves et al., 1991; Schenkman et al., 1991; Abuin et al., 1996a,b; Torrecilhas et al., 2009, 2012; Cánepa et al., 2012a; Maeda et al., 2012; Bayer-Santos et al., 2013; Marcilla et al., 2014; Mattos et al., 2014), peptidyl prolyl cis-trans-isomerase (Moro et al., 1995), oligopeptidases and proteases (Meirelles et al., 1992; Caler et al., 1998; Scharfstein et al., 2000; Cuevas et al., 2003; Bastos et al., 2005; Doyle et al., 2011; Maeda et al., 2014), phospolipases A1 and C (Andrews et al., 1988; Rosenberg et al., 1991; Furuya et al., 2000; Okura et al., 2005; Belaunzarán et al., 2007, 2013; Castillo et al., 2013); mucins and mucin-like proteins (Gazzinelli et al., 1991; de Diego et al., 1997; Kierszenbaum et al., 1999; Pereira-Chioccola et al., 2000; Kierszenbaum et al., 2002; Alcaide and Fresno, 2004; Cánepa et al., 2012b), MASP (de Pablos et al., 2011; Cánepa et al., 2012a), SAP (Baida et al., 2006; Zanforlin et al., 2013), P21 AMA specific proteins (da Silva et al., 2009), surface membrane proteins (TcSMP; Martins et al., 2015); (ii) immune evasion (Andrews et al., 1990; Norris et al., 1991; Norris and Schrimpf, 1994; Ouaissi et al., 1995; Reina-SanMartin et al., 2000; Martin et al., 2006; Mott et al., 2011; Kulkarni et al., 2013; Nogueira et al., 2015); and (iii) increased heart parasitism, inflammation, and arrhythmia that contribute to the pathogenesis of Chagas disease (Torrecilhas et al., 2009; Nogueira et al., 2015; Rodriguez-Angulo et al., 2015). In addition, some of the secreted/excreted proteins are diagnostic markers for Chagas disease (Jazin et al., 1995; Umezawa et al., 1996; Agusti et al., 2000; Bernabó et al., 2013). This mini review will focus on specific molecules secreted by T. cruzi that have already been identified as interfering with host cell signaling and that ultimately play a role in the ability of $T$. cruzi to evade the immune system.

\section{T. cruzi Cruzipain: A Role in Evading the Host Immune Response and Promoting Survival in Cardiomyocytes}

To facilitate their entry into non-phagocytic cells, infectious TCTs employ an arsenal of surface glycoproteins, secreted proteases, and signaling agonists to actively manipulate multiple host cell signaling pathways (Burleigh and Woolsey, 2002). Several studies using synthetic irreversible cysteine peptidase inhibitors have demonstrated that T. cruzi infectivity, host immune evasion, and intracellular growth depend on the activity of cruzipain (Meirelles et al., 1992; Waghabi et al., 2005; McKerrow et al., 2008). To facilitate entry into non-phagocytic cells like endothelial cells and cardiomyocytes, cruzipain acts on a cell-bound kininogen to generate bradykinin, which upon recognition by the $\mathrm{B} 2$ bradykinin receptor, triggers the $\mathrm{Ca}^{2+}$ 
mobilization required for parasite internalization (Scharfstein et al., 2000; Guiñazú et al., 2007; Maeda et al., 2014).

Murine macrophages stimulated with cruzipain up-regulate arginase activity and increase production of IL-10 and TGF$\beta$, thereby increasing T. cruzi survival (Stempin et al., 2002). TGF- $\beta$ in particular can suppress some of the microbicidal functions of macrophages and is one way that parasites create a favorable cellular microenvironment to gain a survival advantage (Gantt et al., 2003; Waghabi et al., 2005). Previous studies have demonstrated that forms of $T$. cruzi are able to activate latent TGF- $\beta$ (Waghabi et al., 2005). Treatment of macrophages with increasing doses of cruzipain promoted the activation of TGF$\beta$ in a dose-dependent manner, confirming that this peptidase is capable of activating latent TGF- $\beta$ in the absence of any other host or parasite factors (Ferrão et al., 2015). In addition, transgenic EPIs overexpressing chagasin, a natural cruzipain inhibitor, were significantly less able to activate latent TGF- $\beta$ when compared to wild type parasites (Santos et al., 2005; Ferrão et al., 2015).

The role of cruzipain in cell entry and TGF- $\beta$ production suggest that it may function during the early events of macrophage infection to facilitate parasite survival and replication. Taken together, the data suggests that cruzipain is a potential pharmaceutical target as it may have an essential role in the pathogenesis of Chagas disease (Guiñazú et al., 2007; Doyle et al., 2011). Based on this evidence, cruzipain inhibitors are considered promising anti-T. cruzi chemotherapeutic agents (Ndao et al., 2014; Branquinha et al., 2015). Irreversible cruzipain inhibitors, such as the prototype molecule K777 (also known as K11777) have been efficacious in experimental models of T. cruzi infection (Engel et al., 1998; Barr et al., 2005; Doyle et al., 2011).

In parallel to the immunological findings, cruzipain promotes cardiomyocyte survival via the PI3K and MEK1-dependent signaling pathways (Aoki et al., 2004, 2006). Cardiomyocytes were pretreated with PI3K or MAPK inhibitors and grown in the presence or absence of cruzipain. Cardiomyocyte apoptosis was decreased after cruzipain treatment, but this protective effect was reduced by incubation with PI3K and MEK1 inhibitors, which had no effect on cruzipain-mediated cardiomyocyte survival in the absence of cruzipain. These findings suggest the survival effects of cruzipain are regulated by effector proteins downstream of PI3K and MEK1. Moreover, T. cruzi infection as well as cruzipain itself mediates the phosphorylation of ERK1/2 and Akt, and cruzipain inhibits proteolytic cleavage of caspase 3 via PI3K and MEK1-dependent signaling pathways (Fujio et al., 2000; Aoki et al., 2006). Together the data strongly suggest cruzipain mediates survival in part via antiapoptotic PI3K/MEK1 signaling. Another study has shown that the anti-apoptotic effect of cruzipain is also mediated in part by arginase activity and Bcl-2 expression (Aoki et al., 2004). Thus, cruzipain activates at least two signaling pathways leading to enhanced cardiomyocyte survival. Parallel activation of these signal transduction pathways may represent a cellular strategy to amplify survival signals in the target cell. Elucidating the pro-survival pathways may lead to a better understanding of the parasite-host relationship and may provide useful targets for the treatment of Chagas disease (Aoki et al., 2004, 2006).

\section{T. cruzi Phospholipase A1: A Role in Activating Host Protein Kinase C (PKC) Throughout Infection}

Phospholipases play a critical role in some physiological processes including the generation of signaling lipids that are relevant to disease (Dennis, 2015). In the case of T. cruzi, phospholipid degrading enzymes are associated with the inflammatory responses elicited by degenerating AMA nests in the tissues of patients with Chagas disease (Wainszelbaum et al., 2001).

Throughout its life cycle, T. cruzi has to adapt to different environments through morphological and functional changes that involve complex networks of enzymatic pathways, including phospholipases. T. cruzi Phospholipase A1 (Tc-PLA1) is secreted by the parasite into the extracellular medium and shows remarkably higher membrane-bound activity in infectious AMAs and TCTs (Wainszelbaum et al., 2001; Belaunzarán et al., 2007). In VERO cells, treatment with Tc-PLA1 and PMA (phorbol 12myristate 13-acetate), a known PKC activator, demonstrated that Tc-PLA1 is involved in host cell lipid modifications leading to PKC activation (34). Tc-PLA1 significantly modified the host cell lipid profile by generating secondary lipid messengers (DG, FFA, and LPC) and concomitant PKC activation. PKC has been implicated in increased parasite invasion, suggesting that Tc-PLA1 is involved in the early events of parasite-host cell interaction preceding parasite invasion (Belaunzarán et al., 2007). Specific anti- Tc-PLAl antibodies can bind to the surface of the parasite and neutralize Tc-PLA1 activity, preventing parasite invasion. This suggests that Tc-PLA1 is an emerging virulence factor for T. cruzi and emphasizes the promise of Tc-PLA1 as a potential therapeutic target (Belaunzarán et al., 2007). Taking these findings into consideration, Tc-PLA1-mediated host cell PKC activation could modulate $\mathrm{Ca}^{2+}$ release from intracellular stores thereby contributing to parasite invasion. $\mathrm{Ca}^{2+}$ mobilization, in both host cell and parasite, is required during the internalization process (Villalta et al., 1999; Yoshida, 2006; Souza et al., 2010; Maeda et al., 2012). In addition, T. cruzi infective stages partially incorporated and metabolized LPC, therefore the remaining extracellular LPC might exert a toxic effect on the host cell, reinforcing the involvement of Tc-PLA1 in the pathogenesis. In this concern, it has been described that LPC inhibits nitric oxide production by $T$. cruzi stimulated macrophages (Figure 1), and thus interferes with the vertebrate host immune system (Belaunzarán et al., 2007).

\section{Secreted T. cruzi Cyclophilin Inactivates the Lytic Vector Defense}

Trypanosoma cruzi not only has to interact with the mammalian host but also with its insect vector (Triatoma infestans), and many of these interactions are still unknown. Innate immune cationic antimicrobial peptides (CAMPs) are expressed by a wide variety of insects to prevent microbial colonization and infection. Several CAMPs have been identified from the saliva, hemolymph, and intestinal tract of reduviid insects (Lopez et al., 2003). Kulkarni et al. (2013) studied the interactions between CAMPs and T. cruzi, and found a unique parasite-driven pathway that modified host CAMPs. Parasites exposed to cyclophilin-trialysin 


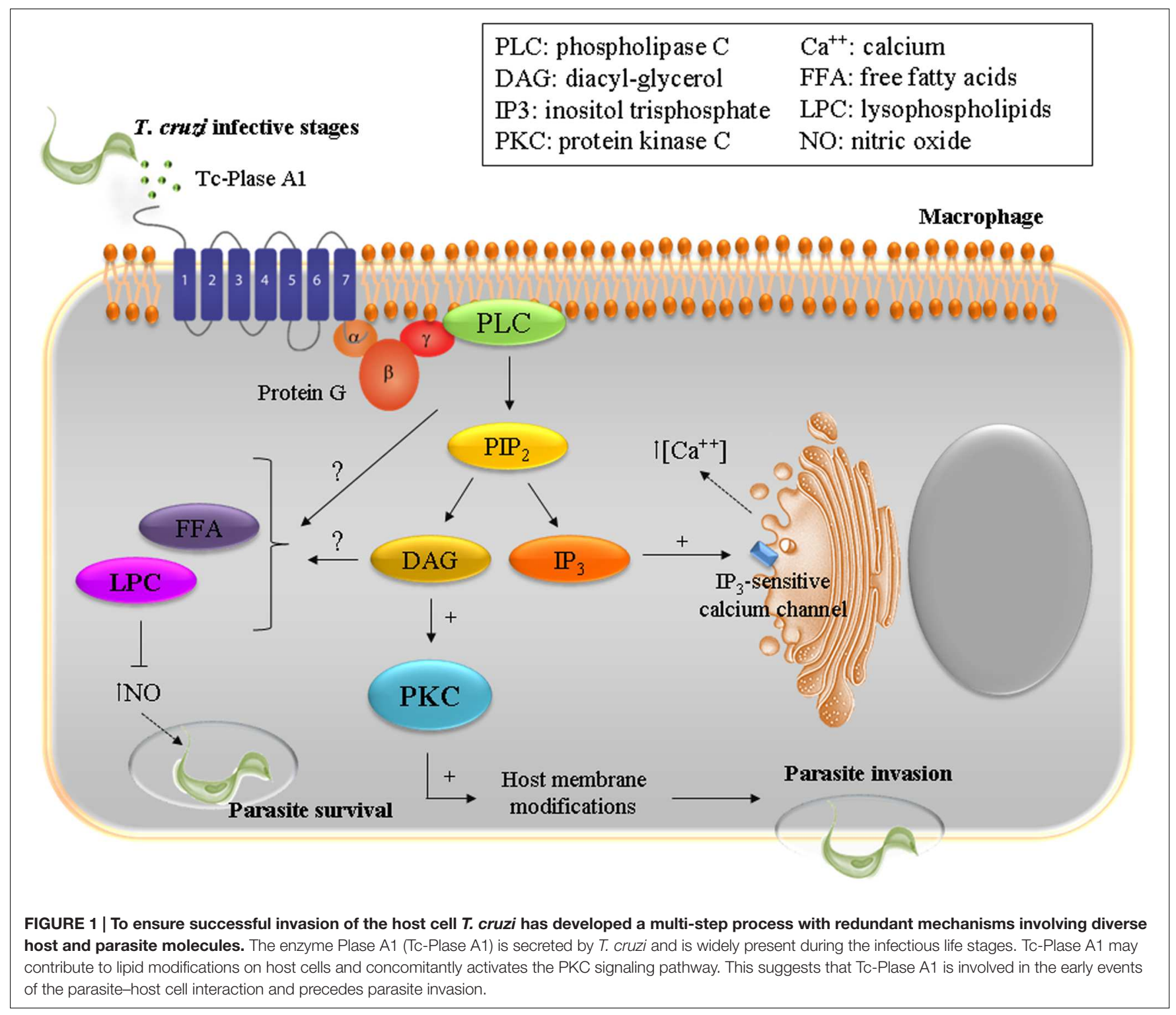

have enhanced binding and invasion in myoblasts pre-grown leading to higher infectivity. They found that secreted parasite cyclophilin, a peptidyl-prolyl isomerase involved in protein folding (Kulkarni et al., 2013; Carraro et al., 2015), binds to and inactivates trialysin via its proline residue. Replicating insectstage parasites secrete cyclophilin 19 as they migrate through the reduviid gastrointestinal tract. Cyclophilin 19 binds to and isomerizes the CAMP peptide neutralizing its anti-parasitic activity. The cyclophilin-trialysin complex then synergistically acts on the parasites to activate calcineurin phosphatase signaling, which drives metabolic activation and ATP production leading to enhanced infectivity. This parasite pathway is a mechanism of CAMP recognition, evasion, and adaptation mediated through calcineurin intracellular signaling (Kulkarni et al., 2013; Carraro et al., 2015). These findings also represent one of the few descriptions of specific stimuli that enhance infectivity of T. cruzi and indicate a defined host molecule-based environmental sensing mechanism in this group of organisms (Kulkarni et al., 2013).

\section{T. cruzi Soluble Factors: Effects on the Host Extracellular Matrix}

Trypomastigotes trigger rapid changes in the host cell signaling pathways during their early interactions with mammalian host cells to facilitate the process of parasite entry into nonprofessional phagocytic cells (Giddings et al., 2006; Yoshida, 2008). However, T. cruzi also affects the host cell downstream of the invasion process. Transcriptional profiling of T. cruziinfected fibroblasts showed that the earliest detectable changes triggered by infectious TCTs involved downregulation of a small subset of genes including members of the CCN family (cyr61 and ctgf/ccn2) that play critical roles in cardiovascular development (angiogenesis), injury repair, fibrotic disease, and extracellular matrix (ECM) homeostasis (Chen and Lau, 2009; 
Mott et al., 2011). Connective tissue growth factor (CTGF/CCN2) promotes cell proliferation and cooperates with TGF- $\beta$ to promote myofibroblast differentiation and enhanced ECM synthesis. Mott et al. (2011) showed that T. cruzi may release a factor that inhibits TGF- 3 -mediated expression of CTGF/CCN2. The expression of CTGF/CCN2 is also controlled by the ETS family of transcriptional factors, which are regulated through MAP kinase signaling. T. cruzi-dependent abrogation of CTGF/CCN2 expression in human dermal fibroblasts is associated with inhibition of both basal and agonist-induced activation of MAP kinase signaling (Mott et al., 2011). T. cruzimediated down-regulation of CTGF expression requires de novo host cell protein synthesis, indicating that the ability of T. cruzi to interfere with the host fibrogenic response is a complex process requiring input from multiple host cell signaling pathways (Unnikrishnan and Burleigh, 2004; Mott et al., 2011).

Regarding the impact of $T$. cruzi secreted factors on TGF- $\beta$-induced fibroblast gene expression, a discrete subset of agonist-inducible fibroblast genes are sensitive to factors secreted/released by $T$. cruzi. A study reports that the group of TGFß-inducible genes that exhibit the highest sensitivity to a T. cruzi secreted/released fraction are MAP kinaseregulated genes that function in wound repair, ECM remodeling, and host response pathways. Inhibition of ECM synthesis because of these secreted parasite factors would facilitate dissemination from early sites of infection (Mott et al., 2011).

\section{Secreted T. cruzi P21 Enhances Host Phagocytosis}

P21 is a secreted protein expressed in all of the developmental stages in the $T$. cruzi lifecycle that may play an important role in parasite internalization (da Silva et al., 2009). Rodrigues et al. (2012) engineered a recombinant protein based on P21 (P21-His6) and then assessed its ability to upregulate phagocytosis in macrophages and alter host cell signaling. P21-His6 upregulated phagocytosis in macrophages in a manner dependent on CXCR4-binding and actin polymerization, and triggered the PI3K signaling pathway (Rodrigues et al., 2012). P21-His6 required PI3K signaling independent of AKT for its function (Vasudevan et al., 2009; Lee et al., 2011). PI3Kdependent signal transduction through the Rho-family GTPases occurs during FcR-mediated phagocytosis and that PI3Kdependent deactivation of Cdc42 is necessary for phagocytosis. Moreover, the activities of PI3K and Cdc42 are linked: FcRactivated Cdc42 stimulates PI3K, which increases concentrations of $\mathrm{PI}(3,4,5) \mathrm{P} 3$ in phagocytic cups, allowing the $\mathrm{PI}(3,4,5) \mathrm{P} 3$ dependent deactivation of $\mathrm{Cdc} 42$ that is necessary to complete phagocytosis (Beemiller et al., 2010). In addition, previous work has provided evidence of PI3K activation in nonprofessional phagocytic cells during $T$. cruzi cell invasion (Woolsey et al., 2003; Rodrigues et al., 2012). In sum, P21 serves as part of the host cell invasion machinery by triggering actin polymerization on the host cell through interactions with the CXCR4 chemokine receptor on the cell membrane, and favoring its own phagocytosis into the host (dos Santos et al., 2014).

\section{T. cruzi MASP: A Role in Evading Host Immune Cells}

The annotation of the $T$. cruzi genome revealed a new multigene family composed of approximately 1,300 genes, which became known as MASPs because they were clustered with genes encoding mucins and other surface protein families (El-Sayed et al., 2005). MASP proteins are GPI-anchored glycoproteins expressed on the surface of the circulating infectious forms of the parasite that can be secreted into the extracellular medium (Bartholomeu et al., 2009; dos Santos et al., 2012; Serna et al., 2014). MASP is the second largest gene family (1377 genes and 433 pseudogenes), representing approximately $6 \%$ of the T. cruzi genome (Serna et al., 2014).

dos Santos et al. (2012) using antibody recognition of several MASP peptides observed the interaction of these proteins with the host immune system during acute T. cruzi infection. The MASP family may play a role in promoting the polyclonal lymphocyte activation that leads to hypergammaglobulinemia and the delayed specific humoral immune response, characteristic of the acute phase of Chagas disease. Polyclonal B-cell activation might diffuse the immune response, preventing the development of a specific and neutralizing response against the parasite and its complete elimination. Additionally, MASP peptides could possibly mediate both specific T-cell dependent and non-specific T-cell independent immune responses. This hypothesis is partially supported by the differential recognition of MASPs by immunoglobulin (Ig) $\mathrm{M}$ and IgG and the difference in the antibody affinity levels against each of the synthetic peptides. All of these phenomena are suggestive of an immune evasion mechanism (Reina-San-Martin et al., 2000; Minoprio, 2001; Gao et al., 2002; dos Santos et al., 2012).

\section{CONCLUDING REMARKS}

Host cell invasion and parasite internalization are important steps in the evolution of parasitism by several pathogens. These processes present at least two important advantages: protection against the host immune response and access to a microenvironment rich in metabolic products (Barrias et al., 2012). Substantial progress has been made in understanding the roles of secreted proteins in infection and invasion by pathogenic T. cruzi. Host cell intracellular signaling can combat the infection; but it can also favor parasite entry. Parasites hijack the host immune response, phagocytosis, ECM, and antiparasitic proteins for their own survival, replication, and immune evasion purposes. The complex networks are interconnected and require extensive study to identify intracellular rearrangements that facilitate parasite internalization; the tools in use today include bioinformatics, novel molecular level studies, and new experimental drugs. A multidisciplinary approach to understanding parasite host interaction will be critical to 
better understand T. cruzi physiopathology, diagnosis, and treatment.

\section{AUTHOR CONTRIBUTIONS}

All authors listed conceived and wrote the manuscript.

\section{REFERENCES}

Abuin, G., Colli, W., and Alves, M. J. (1996a). Turnover and shedding of the Tc-85 surface glycoprotein of Trypanosoma cruzi trypomastigotes. Braz. J. Med. Biol. Res. 29, 335-341.

Abuin, G., Couto, A. S., de Lederkremer, R. M., Casal, O. L., Galli, C., Colli, W., et al. (1996b). Trypanosoma cruzi: the Tc- 85 surface glycoprotein shed by trypomastigotes bears a modified glycosylphosphatidylinositol anchor. Exp. Parasitol. 82, 290-297. doi: 10.1006/expr.1996.0036

Affranchino, J. L., Ibanez, C. F., Luquetti, A. O., Rassi, A., Reyes, M. B., Macina, R. A., et al. (1989). Identification of a Trypanosoma cruzi antigen that is shed during the acute phase of chagas' disease. Mol. Biochem. Parasitol. 34, 221-228. doi: 10.1016/0166-6851(89)90050-9

Agusti, R., Couto, A. S., Alves, M. J., Colli, W., and Lederkremer, R. M. (2000). Lipids shed into the culture medium by trypomastigotes of Trypanosoma cruzi. Mem. Inst. Oswaldo Cruz 97:e102.

Alcaide, P., and Fresno, M. (2004). The Trypanosoma cruzi membrane mucin $\mathrm{AgC} 10$ inhibits $\mathrm{T}$ cell activation and IL-2 transcription through L-selectin. Int. Immunol. 16, 1365-1375. doi: 10.1093/intimm/dxh138

Andrews, N. W., Abrams, C. K., Slatin, S. L., and Griffiths, G. (1990). A T. cruzisecreted protein immunologically related to the complement component C9: evidence for membrane pore-forming activity at low pH. Cell 61, 1277-1287. doi: 10.1016/0092-8674(90)90692-8

Andrews, N. W., Robbins, E. S., Ley, V., Hing, K. S., and Nussenzweig, V. (1988). Developmental regulated phospholipase-C mediated release of the major surface glycoprotein of amastigotes of Trypanosoma cruzi. J. Exp. Med. 167, 300-314. doi: 10.1084/jem.167.2.300

Aoki, M. P., Cano, R. C., Pellegrini, A. V., Tanos, T., Guiñazú, N. L., Coso, O. A., et al. (2006). Different signaling pathways are involved in cardiomyocyte survival induced by a Trypanosoma cruzi glycoprotein. Microbes Infect. 8, 1723-1731. doi: 10.1016/j.micinf.2006.02.010

Aoki, M. P., Guiñazú, N. L., Pellegrini, A. V., Gotoh, T., Masih, D. T., and Gea, S. (2004). Cruzipain, a major Trypanosoma cruzi antigen, promotes arginase-2 expression and survival of neonatal mousecardiomyocytes. Am. J. Physiol. Cell Physiol. 286, C206-C212. doi: 10.1152/ajpcell.00282.2003

Baida, R. C., Santos, M. R., Carmo, M. S., Yoshida, N., Ferreira, D., Ferreira, A. T., et al. (2006). Molecular characterization of serine-, alanine-, and proline-rich proteins of Trypanosoma cruzi and their possible role in host cell infection. Infect. Immun. 74, 1537-1546. doi: 10.1128/IAI.74.3.1537-1546 .2006

Barr, S. C., Warner, K. L., Kornreic, B. G., Piscitelli, J., Wolfe, A., Benet, L., et al. (2005). A cysteine protease inhibitor protects dogs from cardiac damage during infection by Trypanosoma cruzi. Antimicrob. Agents Chemother. 49, 5160-5161. doi: 10.1128/AAC.49.12.5160-5161.2005

Barrias, E. S., Reignault, L. C., De Souza, W., and Carvalho, T. M. (2012). Trypanosoma cruzi uses macropinocytosis as an additional entry pathway into mammalian host cell. Microbes Infect. 14, 1340-1351. doi: 10.1016/j.micinf.2012.08.003

Bartholomeu, D. C., Cerqueira, G. C., Leao, A. C., daRocha, W. D., Pais, F. S., Macedo, C., et al. (2009). Genomic organization and expression profile of the mucin-associated surface protein (masp) family of the human pathogen Trypanosoma cruzi. Nucleic Acids Res. 37, 3407-3417. doi: 10.1093/nar/ gkp172

Bastos, I. M., Grellier, P., Martins, N. F., Cadavid-Restrepo, G., de Souza-Ault, M. R., Augustyns, K., et al. (2005). Molecular, functional and structural properties of the prolyl oligopeptidase of Trypanosoma cruzi (POP Tc80), which is required for parasite entry into mammalian cells. Biochem. J. 388(Pt 1), 29-38. doi: 10.1042/BJ20041049

\section{ACKNOWLEDGMENTS}

The authors wish to thank the support of FAPESP (07/50551-2, 11/51475-3) and CAPES. JFS and DB are recipients of $\mathrm{CNPq}$ fellowships. Authors also thank BioMed Proofreading (http://www.biomedproof reading.com).

Bayer-Santos, E., Aguilar-Bonavides, C., Rodrigues, S. P., Cordero, E. M., Marques, A. F., Varela-Ramirez, A., et al. (2013). Proteomic analysis of Trypanosoma cruzi secretome: characterization of two populations of extracellular vesicles and soluble proteins. J. Proteome Res. 12, 883-897. doi: 10.1021/ pr300947g

Beemiller, P., Zhang, Y., Mohan, S., Levinsohn, E., Gaeta, I., Hoppe, A. D., et al. (2010). A Cdc42 activation cycle coordinated by PI 3-kinase during fc receptormediated phagocytosis. Mol. Biol. Cell 21, 470-480. doi: 10.1091/mbc.E08-050494

Belaunzarán, M. L., Wainszelbaum, M. J., Lammel, E. M., Gimenez, G., Aloise, M. M., Florin-Christensen, J., et al. (2007). Phospholipase A1 from Trypanosoma cruzi infective stages generates lipid messengers that activate host cell protein kinase c. Parasitology 134, 491-502. doi: $10.1017 /$ S0031182006001740

Belaunzarán, M. L., Wilkowsky, S. E., Lammel, E. M., Giménez, G., Bott, E., Barbieri, M. A., et al. (2013). Phospholipase A1: a novel virulence factor in Trypanosoma cruzi. Mol. Biochem. Parasitol. 187, 77-86. doi: 10.1016/j.molbiopara.2012.12.004

Bernabó, G., Levy, G., Ziliani, M., Caeiro, L. D., Sánchez, D. O., and Tekiel, V. (2013). TcTASV-C, a protein family in Trypanosoma cruzi that is predominantly trypomastigote-stage specific and secreted to the medium. PLoS ONE 8:e71192. doi: 10.1371/journal.pone.0071192

Branquinha, M. H., Oliveira, S. S., Sangenito, L. S., Sodre, C. L., Kneipp, L. F., d'Avila-Levy, C. M., et al. (2015). Cruzipain: an update on its potential as chemotherapy target against the human pathogen Trypanosoma cruzi. Curr. Med. Chem. 22, 2225-2235. doi: 10.2174/09298673226661505210 91652

Burleigh, B. A., and Woolsey, A. M. (2002). Cell signaling and Trypanosoma cruzi invasion. Cell Microbiol. 4, 701-711. doi: 10.1046/j.1462-5822.2002. 00226.x

Caler, E. V., Vaena de Avalos, S., Haynes, P. A., Andrews, N. W., and Burleigh, B. A. (1998). Oligopeptidase B-dependent signaling mediates host cell invasion by Trypanosoma cruzi. EMBO J. 17, 4975-4986. doi: 10.1093/emboj/17. 17.4975

Cánepa, G. E., Degese, M. S., Budu, A., Garcia, C. R. S., and Buscaglia, C. A. (2012a). Involvement of TSSA (trypomastigote small surface antigen) in Trypanosoma cruzi invasion of mammalian cells. Biochem. J. 444, 211-218. doi: 10.1042/BJ20120074

Cánepa, G. E., Mesías, A. C., Yu, H., Chen, X., and Buscaglia, C. A. (2012b). Structural features affecting trafficking, processing, and secretion of Trypanosoma cruzi mucins. J. Biol. Chem. 287, 26365-26376. doi: 10.1074/jbc.M112.354696

Carraro, R., Iribarne, F., and Paulino, M. (2015). Analysis of cyclosporin A and a set of analogs as inhibitors of a T. cruzi cyclophilin by docking and molecular dynamics. J. Biomol. Struct. Dyn. 5, 1-15. doi: 10.1080/07391102.2015.10 38584

Castillo, C., Villarroel, A., Duaso, J., Galanti, N., Cabrera, G., Maya, J. D., et al. (2013). Phospholipase $\mathrm{C}$ gamma and ERK1/2 mitogen activated kinase pathways are differentially modulated by Trypanosoma cruzi during tissue invasion in human placenta. Exp. Parasitol. 133, 12-17. doi: 10.1016/j.exppara.2012.10.012

Chen, C. C., and Lau, L. F. (2009). Functions and mechanisms of action of CCN matricellular proteins. Int. J. Biochem. Cell Biol. 41, 771-783. doi: 10.1016/j.biocel.2008.07.025

Clayton, J. (2010). Chagas disease 101. Nature 465, S4-S5. doi: 10.1038 /nature 09220

Cuevas, I. C., Cazzulo, J. J., and Sanchez, D. O. (2003). Gp63 homologues in Trypanosoma cruzi: surface antigens with metalloprotease activity and 
a possible role in host cell infection. Infect. Immun. 71, 5739-5749. doi: 10.1128/IAI.71.10.5739-5749.2003

de Almeida, M. L., and Heise, N. (1993). Proteins anchored via glycosylphosphatidylinositol and solubilizing phospholipases in Trypanosoma cruzi. Biol. Res. 26, 285-312.

de Diego, J., Punzón, C., Duarte, M., and Fresno, M. (1997). Alteration of macrophage function by a Trypanosoma cruzi membrane mucin. J. Immunol. 159, 4983-4989.

de Pablos, L. M., Gonzalez, G. G., Solano Parada, J., Seco Hidalgo, V., Diaz Lozano, I. M., Gomez Samblas, M. M., et al. (2011). Differential expression and characterization of a member of the mucin-associated surface protein family secreted by Trypanosoma cruzi. Infect. Immun. 79, 3993-4001. doi: 10.1128/IAI.05329-11

da Silva, C. V., Kawashita, S. Y., Probst, C. M., Dallagiovanna, B., Cruz, M. C., da Silva, E. A., et al. (2009). Characterization of a $21 \mathrm{kDa}$ protein from Trypanosoma cruzi associated with mammalian cell invasion. Microbes Infect. 11, 563-570. doi: 10.1016/j.micinf.2009.03.007

da Silveira, J. F., Abrahamsohn, P. A., and Colli, W. (1979). Plasma membrane vesicles isolated from epimastigote forms of Trypanosoma cruzi. Biochim. Biophys. Acta 550, 222-232. doi: 10.1016/0005-2736(79) 90209-8

Dennis, E. A. (2015). Introduction to thematic review series: phospholipases: central role in lipid signaling and disease. J. Lipid Res. 56, 1245-1247. doi: 10.1194/jlr.E061101

dos Santos, M. A., Teixeira, F. B., Moreira, H. H., Rodrigues, A. A., Machado, F. C., Clemente, T. M., et al. (2014). A successful strategy for the recovering of active P21, an insoluble recombinant protein of Trypanosoma cruzi. Sci. Rep. 4:4259. doi: $10.1038 /$ srep04259

dos Santos, S. L., Freitas, L. M., Lobo, F. P., Rodrigues-Luiz, G. F., Mendes, T. A., Oliveira, A. C., et al. (2012). The MASP family of Trypanosoma cruzi: changes in gene expression and antigenic profile during the acute phase of experimental infection. PLoS Negl. Trop. Dis. 6:e1779. doi: 10.1371/journal.pntd. 0001779

Doyle, P. S., Zhou, Y. M., Hsieh, I., Greenbaum, D. C., McKerrow, J. H., and Engel, J. C. (2011). The Trypanosoma cruzi protease cruzain mediates immune evasion. PLoS Pathog. 7:e1002139. doi: 10.1371/journal.ppat. 1002139

El-Sayed, N. M., Myler, P. J., Bartholomeu, D. C., Nilsson, D., Aggarwal, G., Tran, A. N., et al. (2005). The genome sequence of Trypanosoma cruzi, etiologic agent of chagas disease. Science 309, 409-415. doi: 10.1126/science. 1112631

Engel, J. C., Doyle, P. S., Hsieh, I., and McKerrow, J. H. (1998). Cysteine protease inhibitors cure an experimental Trypanosoma cruzi infection. J. Exp. Med. 188, 725-734. doi: 10.1084/jem.188.4.725

Ferrão, P. M., d'Avila-Levy, C. M., Araujo-Jorge, T. C., Degrave, W. M., Gonçalves Ada, S., Garzoni, L. R., et al. (2015). Cruzipain activates latent TGF- $\beta$ from host cells during T. cruzi invasion. PLoS ONE 10:e124832. doi: 10.1371/journal.pone.0124832

Fujio, Y., Nguyen, T., Wencker, D., Kitsis, R. N., and Walsh, K. (2000). Akt promotes survival of cardiomyocytes in vitro and protects against ischemia-reperfusion injury in mouse heart. Circulation 101, 660-667. doi: 10.1161/01.CIR.101.6.660

Furuya, T., Kashuba, C., Docampo, R., and Moreno, S. N. (2000). A novel phosphatidylinositol-phospholipase $\mathrm{C}$ of Trypanosoma cruzi that is lipid modified and activated during trypomastigote to amastigote differentiation. J. Biol. Chem. 275, 6428-6438. doi: 10.1074/jbc.275. 9.6428

Gantt, K. R., Schultz-Cherry, S., Rodriguez, N., Jeronimo, S. M. B., Nascimento, E. T., Goldman, T. L., et al. (2003). Activation of TGFbeta by Leishmania chagasi: importance for parasite survival in macrophages. J. Immunol. 170, 2613-2620. doi: 10.4049/jimmunol.170. 5.2613

Gao, W., Wortis, H. H., and Pereira, M. A. (2002). The Trypanosoma cruzi trans-sialidase is a $\mathrm{T}$ cell-independent $\mathrm{B}$ cell mitogen and an inducer of non-specific Ig secretion. Int. Immunol. 14, 299-308. doi: 10.1093/intimm/ 14.3.299

Gazzinelli, R. T., Pereira, M. E. S., Romanha, A., Gazzinelli, G., and Brener, Z. (1991). Direct lysis of Trypanosoma cruzi: a novel effector mechanism of protection mediated by human anti-gal antibodies. Parasite Immunol. 13, 345-356. doi: 10.1111/j.1365-3024.1991.tb00288.x

Giddings, O. K., Eickhoff, C. S., Smith, T. J., Bryant, L. A., and Hoft, D. F. (2006). Anatomical route of invasion and protective mucosal immunity in Trypanosoma cruzi conjunctival infection. Infect. Immun. 74, 5549-5560. doi: 10.1128/IAI.00319-06

Gonçalves, M. F., Umezawa, E. S., Katzin, A. M., de Souza, W., Alves, M. J., Zingales, B., et al. (1991). Trypanosoma cruzi: shedding of surface antigens as membrane vesicles. Exp. Parasitol. 72, 43-53. doi: 10.1016/00144894(91)90119-H

Guiñazú, N., Pellegrini, A., Carrera-Silva, E. A., Aoki, M. P., Cabanillas, A. M., Gìronés, N., et al. (2007). Immunisation with a major Trypanosoma cruzi antigen promotes pro-inflammatory cytokines, nitric oxide production and increases TLR2 expression. Int. J. Parasitol. 37, 1243-1254. doi: 10.1016/j.ijpara.2007.03.010

Jazin, E. E., Bontempi, E. J., Sanchez, D. O., Aslund, L., Henriksson, J., Frasch, A. C., et al. (1995). Trypanosoma cruzi exoantigen is a member of a $160 \mathrm{kDa}$ gene family. Parasitology 110(Pt 1), 61-69. doi: 10.1017/S0031182000081051

Kierszenbaum, F., de Diego, J. L., Fresno, M., and Sztein, M. B. (1999). Inhibitory effects of the Trypanosoma cruzi membrane glycoprotein AGC10 on the expression of IL-2 receptor chains and secretion of cytokines by subpopulations of activated human T lymphocytes. Eur. J. Immunol. 29, 1684-1691. doi: 10.1002/(SICI)1521-4141(199905)29:05 > 1684::AID-IMMU1684>3.0.CO;2-7

Kierszenbaum, F., Fresno, M., and Sztein, M. B. (2002). The Trypanosoma cruzi membrane glycoprotein AGC10 inhibits human lymphocyte activation by a mechanism preceding translation of both, interleukin-2 and its high-affinity receptor subunits. Mol. Biochem. Parasitol. 125, 91-101. doi: 10.1016/S01666851(02)00217-7

Kulkarni, M. M., Karafova, A., Kamysz, W., Schenkman, S., Pelle, R., and McGwire, B. S. (2013). Secreted trypanosome cyclophilin inactivates lytic insect defense peptides and induces parasite calcineurin activation and infectivity. J. Biol. Chem. 288, 8772-8784. doi: 10.1074/jbc.M112.421057

Lee, E. J., Kim, N., Kang, K. H., and Kim, J. W. (2011). Phosphorylation/inactivation of PTEN by Akt-independent PI3K signaling in retinal pigment epithelium. Biochem. Biophys. Res. Commun. 414, 384-389. doi: 10.1016/j.bbrc.2011.09.083

Lopez, L., Morales, G., Ursic, R., Wolff, M., and Lowenberger, C. (2003). Isolation and characterization of a novel insect defensin from Rhodnius prolixus, a vector of chagas disease. Insect Biochem. Mol. Biol. 33, 439-447. doi: 10.1016/S09651748(03)00008-0

Maeda, F. Y., Cortez, C., Izidoro, M. A., Juliano, L., and Yoshida, N. (2014). Fibronectin-degrading activity of Trypanosoma cruzi cysteine proteinase plays a role in host cell invasion. Infect. Immun. 82, 5166-5174. doi: 10.1128/IAI.0202214

Maeda, F. Y., Cortez, C., and Yoshida, N. (2012). Cell signaling during Trypanosoma cruzi invasion. Front. Immunol. 28:361. doi:10.3389/fimmu.2012.00361

Marcilla, A., Martin-Jaular, L., Trelis, M., Menezes- Neto, A., Osuna, A., Bernal, D., et al. (2014). Extracellular vesicles in parasitic diseases. J. Extracell. Vesicles 3:25040. doi: $10.3402 /$ jev.v3.25040

Martin, D. L., Weatherly, D. B., Laucella, S. A., Cabinian, M. A., Crim, M. T., Sullivan, S., et al. (2006). CD8+ T-cell responses to Trypanosoma cruzi are highly focused on strain-variant trans-sialidase epitopes. PLoS Pathog. 2:e77. doi: 10.1371/journal.ppat.0020077

Martins, N. O., Souza, R. T., Cordero, E. M., Maldonado, D. C., Cortez, C., Marini, M. M., et al. (2015). Molecular characterization of a novel family of Trypanosoma cruzi surface membrane proteins (TcSMP) involved in mammalian host cell invasion. PLoS Negl. Trop. Dis. 9:e0004216. doi: 10.1371/journal.pntd.0004216

Mattos, E. C., Tonelli, R. R., Colli, W., and Alves, M. J. (2014). The Gp85 surface glycoproteins from Trypanosoma cruzi. Subcell. Biochem. 74, 151-180. doi: 10.1007/978-94-007-7305-9_7

McConville, M. J., Mullin, K. A., Ilgoutz, S. C., and Teasdale, R. D. (2002). Secretory pathway of trypanosomatid parasites. Microb. Mol. Biol. Rev. 66, 122-154. doi: 10.1128/MMBR.66.1.122-154.2002

McKerrow, J. H., Rosenthal, P. J., Swenerton, R., and Doyle, P. (2008). Development of protease inhibitors for protozoan infections. Curr. Opin. Infect. Dis. 21, 668-672. doi: 10.1097/QCO.0b013e328315cca9 
Meirelles, M. N., Juliano, L., Carmona, E., Silva, S. G., Costa, E. M., Murta, A. C., et al. (1992). Inhibitors of the major cysteinyl proteinase (gp57/51) impair host cell invasion and arrest the intracellular development of Trypanosoma cruzi in vitro. Mol. Biochem. Parasitol. 52, 175-184. doi: 10.1016/01666851(92)90050-T

Minoprio, P. (2001). Parasite polyclonal activators: new targets for vaccination approaches? Int. J. Parasitol. 31, 588-591. doi: 10.1016/S0020-7519(01)00171-0

Moro, A., Ruiz-Cabello, F., Fernandez-Cano, A., Stock, R. P., and Gonzalez, A. (1995). Secretion by Trypanosoma cruzi of a peptidyl-prolyl cis-trans isomerase involved in cell infection. EMBO J. 14, 2483-2490.

Mott, A., Costales, J. A., and Burleigh, B. A. (2011). A soluble factor from Trypanosoma cruzi inhibits transforming growth factor-ss-induced MAP kinase activation and gene expression in dermal fibroblasts. PLOS ONE 6:e23482. doi: 10.1371/journal.pone.0023482

Ndao, M., Beaulieu, C., Black, W. C., Isabel, E., Vasquez-Camargo, F., NathChowdhury, M., et al. (2014). Reversible cysteine protease inhibitors show promise for a chagas disease cure. Antimicrob. Agents Chemother. 58, 11671178. doi: 10.1128/AAC.01855-13

Nickel, W., and Seedorf, M. (2008). Unconventional mechanisms of protein transport to the cell surface of eukaryotic cells. Annu. Rev. Cell Dev. Biol. 24, 287-308. doi: 10.1146/annurev.cellbio.24.110707.175320

Nogueira, P. M., Ribeiro, K., Silveira, A. C., Campos, J. H., Martins-Filho, O. A., Bela, S. R., et al. (2015). Vesicles from different Trypanosoma cruzi strains trigger differential innate and chronic immune responses. J. Extracell. Vesicles 4:28734. doi: 10.3402/jev.v4.28734

Norris, K. A., Bradt, B., Cooper, N. R., and So, M. (1991). Characterization of a Trypanosoma cruzi C3 binding protein with functional and genetic similarities to the human complement regulatory protein, decay-accelerating factor. J. Immunol. 147, 2240-2247.

Norris, K. A., and Schrimpf, J. E. (1994). Biochemical analysis of the membrane and soluble forms of the complement regulatory protein of Trypanosoma cruzi. Infect. Immun. 62, 236-243.

Okura, M., Fang, J., Salto, M. L., Singer, R. S., Docampo, R., and Moreno, S. N. (2005). A lipid-modified phosphoinositide-specific phospholipase C (TcPI-PLC) is involved in differentiation of trypomastigotes to amastigotes of Trypanosoma cruzi. J. Biol. Chem. 280, 16235-16243. doi: 10.1074/jbc.M414535200

Ouaissi, A., Guevara-Espinoza, A., Chabe, F., Gomez-Corvera, R., and Taibi, A. (1995). A novel and basic mechanism of immunosuppression in Chagas' disease: Trypanosoma cruzi releases in vitro and in vivo a protein which induces $\mathrm{T}$ cell unresponsiveness through specific interaction with cysteine and glutathione. Immunol. Lett. 48, 221-224. doi: 10.1016/0165-2478(95) 02463-8

Pereira-Chioccola, V. L., Acosta-Serrano, A., Correia de Almeida, I., Ferguson, M. A., Souto-Padron, T., Rodrigues, M. M., et al. (2000). Mucin-like molecules form a negatively charged coat that protects Trypanosoma cruzi trypomastigotes from killing by human anti- $\alpha$-galactosyl antibodies. J. Cell Sci. 113, 1299-1307.

Ponce, N. E., Carrera-Silva, E. A., Pellegrini, A. V., Cazorla, S. I., Malchiodi, E. L., Lima, A. P., et al. (2013). Trypanosoma cruzi, the causative agent of Chagas disease, modulates interleukin-6-induced STAT3 phosphorylation via gp130 cleavage in different host cells. Biochim. Biophys. Acta (BBA) 1832, 485-494. doi: 10.1016/j.bbadis.2012.12.003

Reina-San-Martin, B., Degrave, W., Rougeot, C., Cosson, A., Chamond, N., Cordeiro-Da-Silva, A., et al. (2000). A B-cell mitogen from a pathogenic trypanosome is a eukaryotic proline racemase. Nat. Med. 6, 890-897. doi: $10.1038 / 78651$

Rodrigues, A. A., Clemente, T. M., Dos Santos, M. A., Machado, F. C., Gomes, R. G., Moreira, H. H., et al. (2012). A recombinant protein based on Trypanosoma cruzi P21 enhances phagocytosis. PLoS ONE 7:e51384. doi: 10.1371/journal.pone.0051384

Rodriguez-Angulo, H. O., Toro-Mendoza, J., Marques, J. A., Concepcion, J. L., Bonfante-Cabarcas, R., Higuerey, Y., et al. (2015). Evidence of reversible bradycardia and arrhythmias caused by immunogenic proteins secreted by T. cruzi in isolated rat hearts. PLoS Negl. Trop. Dis. 9:e0003512. doi: 10.1371/journal.pntd.0003512

Rosenberg, I., Prioli, R. P., Ortega-Barria, E., and Pereira, M. E. (1991). Stage-specific phospholipase C-mediated release of Trypanosoma cruzi neuraminidase. Mol. Biochem. Parasitol. 46, 303-305. doi: 10.1016/01666851(91)90054-A

Santos, C. C., Sant'Anna, C., Terres, A., Cunha-e-Silva, N. L., Scharfstein, J., and de Lima, A. P. (2005). Chagasin, the endogenous cysteine-protease inhibitor of Trypanosoma cruzi, modulates parasite differentiation and invasion of mammalian cells. J. Cell Sci. 118, 901-915. doi: 10.1242/jcs.01677

Scharfstein, J., Schmitz, V., Morandi, V., Capella, M. M. A., Lima, A. P. C. A., Morrot, A., et al. (2000). Host cell invasion by Trypanosoma cruzi is potentiated by activation of bradykinin B2 receptors. J. Exp. Med. 192, 1289-1299. doi: 10.1084/jem.192.9.1289

Schenkman, S., Jiang, M.-S., Hart, G. W., and Nussenzweig, V. (1991). A novel cell surface trans-sialidase of Trypanosoma cruzi generates a stage-specific epitope required for invasion of mammalian cells. Cell 65, 1117-1125. doi: 10.1016/0092-8674(91)90008-M

Serna, C., Lara, J. A., Rodrigues, S. P., Marques, A. F., Almeida, I. C., and Maldonado, R. A. (2014). A synthetic peptide from Trypanosoma cruzi mucinlike associated surface protein as candidate for a vaccine against Chagas disease. Vaccine 32, 3525-3532. doi: 10.1016/j.vaccine.2014.04.026

Simpson, R. J., and Mathivanan, S. (2012). Extracellular microvesicles: the need for internationally recognised nomenclature and stringent purification criteria. J. Proteomics Bioinform. 5:1. doi: 10.4172/jpb.10000e10

Souza, W., Carvalho, T. M. U., and Barria, E. S. (2010). Review on Trypanosoma cruzi: host cell interaction. Int. J Cell Biol. 2010:295394. doi: $10.1155 / 2010 / 295394$

Stempin, C., Giordanengo, L., Gea, S., and Cerba, F. (2002). Alternative activation and increase of Trypanosoma cruzi survival in murine macrophages stimulated by cruzipain, a parasite antigen. J. Leukoc. Biol. 72, 727-734.

Torrecilhas, A. C., Schumacher, R. I., Alves, M. J., and Colli, W. (2012). Vesicles as carriers of virulence factors in parasitic protozoan diseases. Microbes Infect. 14, 1465-1474. doi: 10.1016/j.micinf.2012.07.008

Torrecilhas, A. C., Tonelli, R. R., Pavanelli, W. R., da Silva, J. S., Schumacher, R. I., de Souza, W., et al. (2009). Trypanosoma cruzi: parasite shed vesicles increase heart parasitism and generate an intense inflammatory response. Microbes Infect. 11, 29-39. doi: 10.1016/j.micinf.2008.10.003

Umezawa, E. S., Shikanai-Yasuda, M. A., and Stolf, A. M. (1996). Changes in isotype composition and antigen recognition of anti-Trypanosoma cruzi antibodies from acute to chronic chagas disease. J. Clin. Lab. Anal. 10, 407-413. doi: 10.1002/(SICI)1098-2825(1996)10:6 <407::AID-JCLA16>3.3.CO;2-9

Unnikrishnan, M., and Burleigh, B. A. (2004). Inhibition of host connective tissue growth factor expression: a novel Trypanosoma cruzi-mediated response. FASEB J. 18, 1625-1635. doi: 10.1096/fj.04-1554com

Vasudevan, K. M., Barbie, D. A., Davies, M. A., Rabinovsky, R., McNear, C. J., Kim, J. J., et al. (2009). AKT-independent signaling downstream of oncogenic PIK3CA mutations in human cancer. Cancer Cell 16, 21-32. doi: 10.1016/j.ccr.2009.04.012

Villalta, F., Zhang, Y., Bibb, K. E., Pratap, S., Burns, J. M. Jr., and Lima, M. F. (1999). Signal transduction in human macrophages by gp83 ligand of Trypanosoma cruzi: trypomastigote gp83 ligand up-regulates trypanosome entry through protein kinase C activation. Mol. Cell. Biol. Res. Commun. 2, 64-70. doi: 10.1006/mcbr.1999.0150

Waghabi, M. C., Keramidas, M., Bailly, S., Degrave, W., Mendonça-Lima, L., Soeiro, M. N., et al. (2005). Uptake of host cell transforming growth factorbeta by Trypanosoma cruzi amastigotes in cardiomyocytes: potential role in parasite cycle completion. Am. J. Pathol. 167, 993-1003. doi: 10.1016/S00029440(10)61189-3

Wainszelbaum, M., Isola, E., Wilkowsky, S., Cannata, J. J., FlorinChristensen, J., and Florin-Christensen, M. (2001). Lysosomal phospholipase A1 in Trypanosoma cruzi: an enzyme with a possible role in the pathogenesis of Chagas disease. Biochem. J. 355, 765-770. doi: 10.1042/bj3 550765

Woolsey, A. M., Sunwoo, L., Petersen, C. A., Brachmann, S. M., Cantley, L. C., and Burleigh, B. A. (2003). Novel PI 3-kinase-dependent mechanisms of trypanosome invasion and vacuole maturation. J. Cell Sci. 116(Pt 17), 3611-3622. doi: 10.1242/jcs.00666

Yoshida, N. (2006). Molecular basis of mammalian cell invasion by Trypanosoma cruzi. An. Acad. Bras. Cienc. 78, 87-111. doi: 10.1590/S0001-37652006000100010 
Yoshida, N. (2008). Trypanosoma cruzi infection by oral route: how the interplay between parasite and host components modulates infectivity. Parasitol. Int. 57, 105-109. doi: 10.1016/j.parint.2007.12.008

Zanforlin, T., Bayer-Santos, E., Cortez, C., Almeida, I. C., Yoshida, N., and da Silveira, J. F. (2013). Molecular characterization of Trypanosoma cruzi SAP proteins with host-cell lysosome exocytosis-inducing activity required for parasite invasion. PLoS ONE 8:e83864. doi: 10.1371/journal.pone.0083864

Zingales, B., Katzin, A. M., Arruda, M. V., and Colli, W. (1985). Correlation of tunicamycin-sensitive surface glycoproteins from Trypanosoma cruzi with parasite interiorization into mammalian cells. Mol. Biochem. Parasitol. 16, 21-34. doi: 10.1016/0166-6851(85)90046-5
Conflict of Interest Statement: The authors declare that the research was conducted in the absence of any commercial or financial relationships that could be construed as a potential conflict of interest.

Copyright (c) 2016 Watanabe Costa, da Silveira and Bahia. This is an open-access article distributed under the terms of the Creative Commons Attribution License (CC BY). The use, distribution or reproduction in other forums is permitted, provided the original author(s) or licensor are credited and that the original publication in this journal is cited, in accordance with accepted academic practice. No use, distribution or reproduction is permitted which does not comply with these terms. 